\title{
Problem-Based Learning Approach for Elementary Schools: A case study of five Years Compulsory Education system
}

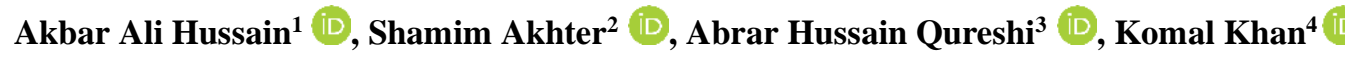 \\ ${ }^{1}$ Faculty of education, university of the Punjab, Lahore, Pakistan. \\ ${ }^{2} \mathrm{Ph} . \mathrm{D}$. Scholar, School of Languages, Civilisation and Philosophy, Universiti Utara Malaysia, Malaysia. \\ ${ }^{3}$ Department of English, University of Sahiwal, Sahiwal, Pakistan. \\ ${ }^{4}$ Lecturer English, Institute of Southern Punjab, Multan, Pakistan.
}

\section{ABSTRACT}

Keywords:

Problem-Based Learning, Elementary Schools, Compulsory Education, Literacy Rate, Pakistan.

\section{Received Date: \\ 06-09-2020}

Accepted Date:

27-10-2020

Publication Date:

31-07-2021
Purpose of Study: The aim of the study is to identify and build an appropriate learning model for elementary school students that will ensure a quiet learning environment.

\begin{abstract}
Methodology: This research used both qualitative and quantitative approaches, as well as research and development techniques. The research was divided into two stages: exploration and experimental studies. Meanwhile, 50 learners, thirteen educational tutors, and six persons from the literacy program administration were chosen for the analysis by purposive sampling.
\end{abstract}

Main Finding: According to the findings of the study, problem-based learning contributed to an increase in literacy in an entrepreneurship literacy program.

Research Implication: The study's findings revealed that PBL implementation was anchored in a learning program and learning management. The discovery also aids in the development of the curriculum's learning methodologies, learning resources, learning media, and learning evaluation.

Novelty/Originality: It is critical to increase literacy abilities in order to read, write, and assess problems. This research examines and describes the problem-based learning technique for developing literacy competency and assisting readers in improving their reading skills.

\section{INTRODUCTION}

Education gives people access to new knowledge, attitudes, and skills, allowing them to make significant changes in their lives (Bandy, 2016). An endeavor to improve education can lead to a better life since it gives people hope (Collins, Bekenova, \& Kagarmanova, 2018). Tawil and Locatelli (2015) considers education to be an endeavour to transform human potential into something useful in response to life's obstacles. This is in line with article 25 (A) of the Republic of Pakistan's Constitution, which states that "every citizen has the right to education," as well as "every person shall have the right to develop himself/herself through the fulfillment of his/her basic needs, through the right to attain education and to benefit from science and technology, arts, and culture, to develop himself/herself through the fulfillment of his/her basic needs, to develop himself/herself through the fulfillment of his/her.

According to the preceding statements, education is a component of human rights that attempts to improve learners' abilities (Robinson, Phillips, \& Quennerstedt, 2020). An individual's quality of life can be improved by education. On the contrary, increased illiteracy rates might make a community's position worse. Because it hinders the development of individual skills, illiteracy has an impact on individuals' and society's life chances (Khalid \& Khan, 2006). Despite the fact that poor literacy levels have an impact on life chances (Ahmad, 2014), illiteracy remains one of Pakistan's major issues. Many pockets of illiteracy can still be found throughout the archipelago, with inadequate reading abilities being prevalent in numerous areas. Inequality in education is the reason of low reading ability (Khalid \& Khan, 2006). It is exemplified by Pakistan's Human Development Index, a condensed measure that assesses long-term growth in three major areas of human development (Ahmad, 2014). Pakistan's HDI value for 201 is 0.557 , automatically placing the country in the high human development category, ranking 154 out of 189 countries and territories worldwide (Ahmad, 2014). Because access to knowledge is a function of education, educational factors such as illiteracy have a significant role in a country's human resource ranking. The current study focuses on the "problem-based learning approach for primary schools as a strategy for achieving a country's required reading competencies." The goal is to describe the efforts made in the fight to produce a knowledgeable citizenry through compulsory education.

An intense illiteracy eradication campaign was implemented as the manifestation of the national movement, with the goal of increasing adult literacy by $50 \%$, starting with those aged 15 and women, and supporting the endeavor to offer equal access to school for everyone (Khalid \& Khan, 2006). As a result, the literacy education program has been and continues to be used to provide educational services to illiterates. Literacy education is an endeavour to realize people's fundamental rights to education as part of their human rights realization. Many entrepreneurship literacy initiatives have been developed and implemented in response to this concept of literacy, with the goal of empowering grassroots communities. The author of this paper discusses an enterprise literacy program that intends to empower illiterates aged 14 and up by enhancing their knowledge, attitudes, and abilities, such as the fundamentals of individual competency development (Mehboob \& Othman, 2020).

${ }^{1}$ Corresponding Author: akbaralih4343@gmail.com

Please cite this article as: Hussain, A, A., Akhter, S., Abrar Hussain Qureshi, A, H., \& Khan, k. (2021). Problem-Based Learning Approach for Elementary Schools: A case study of five Years Compulsory Education system. Journal of Social Sciences and Economic Review, 3(2), 9-14. doi.org/10.36923/ijsser.v3i2.69 
This article is founded on the notion that due to insufficient tactics and techniques in place, the execution of the entrepreneurship literacy program in Pakistan is still limited. The use of traditional methods such as lecturing during the training and learning process; facilitators-dominate in the decision-making process; entrepreneurs with limited business knowledge and skills; and a limited network, coupled with insufficient capital due to poverty, are among the challenges (Afreen, 2021). This research attempts to create a learning model that can help people improve their reading abilities and adapt their businesses to changing situations. Entrepreneurship, as one of the empowerment programs, focuses on the learners' experiences, and the content is a crucial part of the program for business empowerment. As a result of the preceding description, it is assumed that Problem Based Learning is the best strategy for the literacy learning program. The author conducted research in order to analyze and describe the problembased learning approach for the development of literacy competency. The research focused on how the use of problem-based learning can help people improve their reading skills.

\section{LITERATURE REVIEW}

According to the Pakistani Education Law, education is a key component of life development for all citizens, regardless of their circumstances. Those who are unable to obtain formal education, for example, can still do so since the government offers three options: formal education, non-formal education, and informal education. The three education subsystems listed above all work toward the same national aim of educating Pakistanis and improving their quality of life in order to achieve a society that is advanced, fair, and affluent (Aslam, 2011).

In addition, there are other sections in Pakistan's education law that explain the educational system and the development of broader reading skills. Article 26 paragraph (2), for example, indicates that education aims to develop learners' potentials with a focus on learning knowledge and functional skills as well as developing personality and professional attitudes. Following paragraph (2) is a description of the content of non-formal education, which includes life-skills education, early childhood education, youth education, women empowerment education, literacy education, literacy education, vocational training, internships, equivalency programs, and other types of education aimed at developing learner skills. Finally, paragraph (4) discusses non-formal education units including training centers and colleges, study groups, community learning centers, Islamic study circles or groups, and other educational units with similar goals and objectives. As a result, Pakistani education is a wellstructured system with a similar goal and function. The official, non-formal, and informal education subsystems do, however, differ slightly(Aslam, 2011; Bandy, 2016).

Non-formal education, on the other hand, has a learning process that is analogous to formal education. Learning, according to

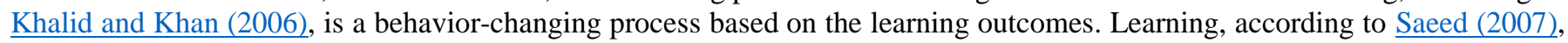
is a continuous change in human performance along with their potentials. When it comes to behavioral changes, Davis and Luthans claim that learning is a generally permanent change that occurs as a result of experience (Khan, Khan, Zia-Ul-Islam, \&

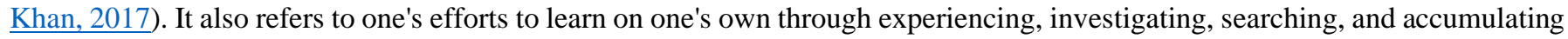
knowledge.

This paper examines literacy skills in the context of educational competency development. Because the current paper examines problem-based learning in the development of learners' competencies in order to complete a five-year compulsory education program, the learning modeling concept used is one that is appropriate for learners' self-reliance, thus examining the adult learners' concept of andragogy. Andragogy is a Greek term that means "adults" and "agogos," which means "to lead" or "to guide."

As stated in the introduction, the goal of this study is to increase reading skills in order to improve capacity, which is believed vital in people's social and professional lives. The ability of citizens to read determines the success of a country's development program. Illiteracy can stifle a country's development goal; as a result, a country's literacy rates must be addressed as soon as possible. Illiteracy is defined as the inability to write and read a basic sentence in everyday life. Literacy, according to Khan et al. (2017), is widely defined as the knowledge and abilities required in a fast-changing environment as part of human rights. He goes on to say that literacy is both a learning facility for lifelong learning and a catalyst for social, cultural, political, economic, and community empowering participation (Khalid \& Khan, 2006). Literacy is referred to as a human right by Robinson et al. (2020). Illiteracy is a serious pandemic that is a hot issue of debate around the world, not just in developing nations but also in developed countries, because it is the root of many societal ills like as poverty, unemployment, conflict, and pressure, as well as social stratification.

The literacy program is designed to increase people's aptitude, comprehension, and self-adjustment in order to help them overcome life's obstacles (Khan et al., 2017). Literacy, in general, attempts to change individuals and communities by offering equitable opportunity and global justice. From this standpoint, all parties' literacy concerns should be addressed by deploying all necessary resources and means. Literacy is also an element of the primary education structure, which aims to educate both educated and uneducated members of society. In the future, traditional literacy education will be transformed into functional literacy education. Literacy, according to Kazmi and Quran (2005), is defined as the ability to write, do elementary math, and read in everyday situations. Meanwhile, functional literacy is defined as the capacity to successfully apply literacy abilities to improve one's situation.

\section{RESEARCH METHODS}

This study took a mixed-methods approach, focusing on a learning design that intends to develop learners' entrepreneurship literacy skills through problem-solving as one of the ways to improve learners' competencies. The author used a few processes from a research and development method to carry out the investigation ( $R$ and $D)$. R and $D$ is a research method for designing or improving a product, according to Gall, Borg, and Gall (1996). A few parts, specifically, the exploratory study stage (preliminary study) and the model creation stage, were borrowed. The purpose of the first phase of the preparatory stage was to gain an overview of the difficulties as well as the program's resources. The conceptual design for the problem-based learning method to improving competency requirements was developed in the second stage. 
The research was carried out in South Kalimantan, with a focus on Banjarmasin's selected areas. The participants included 50 people aged 14 to 60,14 tutors, and six literacy education program participants who were learning material participants. The data source for this study was primary and secondary data, and it used the purposive sampling approach to determine the study's sampling. During the study, primary data was collected directly from respondents through interviews and direct observations. Secondary data, on the other hand, was derived from a variety of sources to supplement the primary data provided by formal and non-formal institutions.

The goal of this project was to create a learning design that would help students enhance their literacy abilities. The design was put to the test in a series of tests before being finalized and recommended. During the test, the quasi-experimental method was used, with pre- and post-test designs against the treatment-treated trial group. The exploratory investigation, conceptual modeling design, conceptual design verification, restricted trial, a field test of the design, and evaluation of its execution were all used to perform the preliminary study qualitatively. The tasks in the second trial involved implementing a revised design in a single-group Pretest-Posttest design employing a quasi-experimental pre-test and post-test design. Finally, the pre-test and posttest outcomes in the piloted group were compared without the use of the control group. The results of the investigation showed that the participants' literacy skills had improved.

\section{RESULTS OF THE STUDY}

\section{a. The Description of Learning Environment}

Non-formal schools, like formal schools, provide a welcoming learning environment that encourages students to learn. The system prioritized knowledge construction, and each member is responsible for actively learning. Individual construction is thought to be more dependable than group construction. Group talks, on the other hand, were able to tackle presented trial issues in a relaxed and amicable manner. The response to the process and performance was based on the idea that a facilitator in the learning process can assist in observing different mindsets during performances, determining when to intervene in activities, and positioning themselves as learners without actively participating in the process.

Several supporting tools were established to support the implementation of the learning design, including an open-ended bank of problems, lesson plans based on Problem Based Learning principles combined with a cooperative approach, learning materials that addressed everyday issues, and learning assessments that recognized the learners' required literacy skill

\section{b. The Planning Step}

Research coordination with the managerial partner, tutor training, learning program preparation, requirements observation, and syllabus preparation, as well as tools and teaching materials preparation, were all steps taken in preparing and planning an entrepreneurship literacy program using the problem-based learning design. First, the researchers worked with the literacy program sponsor to coordinate time, schedule, subjects, curriculum, media, and learning methods.

\section{c. The Implementation Step}

Research coordination with the managerial partner, tutor training, learning program preparation, requirements observation, and syllabus, as well as tools and teaching materials preparation, were all steps taken in preparing and planning an entrepreneurship literacy program using the problem-based learning design. To begin, the research team worked with the literacy program party to coordinate time, schedule, subjects, curriculum, media, and learning technique.

\section{d. The Evaluation Process}

In most cases, the entrepreneurial learning assessment technique followed the Technical Guidance of Literacy Education the assessment established by the Pakistan Ministry of Education's. However, in this program, assessment was done by the tutor at each stage or even the program's practitioner. Learning evaluation, learning outcomes, the program's objectives, the principles, the evaluator, assessment components, assessment instruments, certificates, and mentorship were the elements that were most commonly included in the assessment process.

\section{e.The Effectiveness of the Learning Design}

The average pre-test score for the 50 persons in the sample was 11.05, with a standard deviation of 3,942. The post-test score after implementing problem-based learning was 14.58 , with a standard deviation of 3,500. The findings show that problem-based learning has a considerable impact on Banjarmasin's literacy rate. In other words, the problem-based learning model was successfully implemented. Since $=0,05>\mathrm{Sig} 0000$, the correlation coefficient between the learning score before and after the use of problem-based learning was equal to 0,890 . It denotes that the significance is at a $95 \%$ confidence level. These findings show that enhanced competences are required for entrepreneurship literacy skills.

\section{DISCUSSION}

Entrepreneurship literacy education was a program that aimed to improve individual and group productivity by ensuring that they have the essential literacy skills. The program's targeted beneficiaries were adults who had finished and achieved essential literacy skills, as opposed to youngsters. Furthermore, the literacy education principles of local design, local context, partnership, and functionalization were used to support the learning methodologies used to attain the learning objectives. Literacy learning was apparently inseparable from an adult's daily life, as evidenced by these four principles, and literacy learning materials were functional for each learner. As a result, a desirable learning approach is one that can effectively build learners' personalities. It manifests itself in the ability to express oneself, participate actively, be highly motivated, and participate actively in the completion of duties, whether alone or in groups. 
The learning approach, according to the Nugmanova, Mikkola, Rozanov, and Komleva (2020) can be explained through structured procedures for teaching people to attain the specified learning objectives. During the class, the literacy learning approach was used in an attempt to simplify the procedure. It agrees with the assertion made by Ignoffo et al. (2017) about the andragogy methodology and curriculum. He also stated that while all tactics and procedures are fundamentally correct and may be modified by the tutor throughout the class, none of them are ideal, as each has its own set of benefits and drawbacks. By this time, there was a trend in literacy education to become more learner-centered, with an emphasis on examining people's needs (Brookfield, 1984). As a result, literacy education must provide students with a wide range of life skills and information.

It was required to use an appropriate model based on literacy learning principles, such as problem-based learning, to find the specific expectations of citizens toward literacy education. According to Aslam (2011), problem-based learning has various features, including being problem-oriented and using a tutor rather than a teacher as a facilitator. Although problem-based solutions was not a new concept, it was gaining popularity quickly, particularly among democratic societies and grassroots communities (Alam \& Shakir, 2019). The problem-based-solving design was part of Piaget and Vygotsky's educational paradigm based on the principle of constructive learning. The assumption behind this theory was that knowledge is the consequence of social construction. Humans built their understanding by interacting with objects, phenomena, experiences, and places HDR. (2019 HDR). Citizens' knowledge is acquired through social interaction as a result of problem-solving design. Knowledge is made up of two different viewpoints. First, spontaneous comprehension comes from everyday life, but scientific understanding comes through a formal learning system that is logically defined on a larger scale.

The effectiveness of the problem-solving design was used to assess the learning results in this study. The result of assessing its efficacy reveals whether or not this learning design worked - competency development based on the measurement outcome in learning, which is widely utilized by employers. Learning, according to Akhtar Malik (2019), is a changing process in behavior that is formed based on learning outcomes. Ahmad (2014) feel that problem-solving is more than just instruction; it also incorporates critical thinking, which is an important part of work performance. This has an impact on one's efficacy, which is defined as the value of completing a task. The levels of efficacy should ideally be stated using precise measurements. The understanding of the occurrence of the desired effect or another effect is contained in effectivities. If a person does anything with a specific goal in mind, that person is considered to be effective if the result is what he intended.

The capacity to achieve established goals is referred to as effectiveness. It also considers the advantages of the acquired results, the amount of power, and the level of client happiness. According to the statistical test, the efficiency of problem-based learning has a substantial impact on boosting entrepreneurship literacy ability. The results of the competencies were assessed based on their knowledge and skills, but not on their ability to change attitudes. Bloom defined three types of learning outcomes in his learning taxonomy: cognitive domain, adequate domain, and motor skill domain.

In comparison to traditional learning, the results of the investigation revealed that entrepreneurship literacy skills gained through problem-based learning had a higher value. At the same time, the analyses' outcome acted as shown expertise. Alam and Shakir (2019) divide competency into two categories: threshold competencies and distinguishing competences. Differentiating competence distinguishes learners who have advanced skills from the rest of the population, whereas threshold competencies are the necessary attributes to become competent in a career but not to distinguish from the average.

\section{CONCLUSION}

The study's goal was to create a learning design that would help learners improve their literacy skills. Literacy refers to the capacity to read, write, and do arithmetic, as well as reading comprehension of information and symbols - the planning, execution, and assessment stages of problem-based learning. The research cooperation with the management team, literacy tutoring, learning program preparation, requirements observation, all syllabus, also known as lesson plan preparation, as well as teaching materials and facilities preparation were all detailed in the planning stages. Then, in a similar fashion to formal schooling, learning was implemented in the classroom. The implementation of PBL, on the other hand, was based on a learning program and learning management. The curriculum included learning methodologies, materials, media, and evaluation, with the competence of tutors, practitioners, and adult learners having a significant impact on learning management. All of the learning outcomes were assessed during the evaluation.

\section{REFERENCES}

Afreen, M. (2021). Transition Assessment of the Bangladeshi Financial Market Stress Regimes: A Markov Switching Modeling Approach. International Journal of Social Sciences and Economic Review, 3(1), 07-11.

Ahmad, I. (2014). Critical Analysis of the Problems of Education in Pakistan: Possible Solutions. International Journal of Evaluation and Research in Education, 3(2), 79-84.

Akhtar Malik, N. (2019). Occupational Stress and Burnout among University Teachers in Pakistan and Finland.

Alam, H. R., \& Shakir, M. (2019). Causes of the passive attitude in children at early grade level. International Journal of Social Sciences and Economic Review, 1(1), 16-21.

Aslam, H. D. (2011). Analyzing professional development practices for teachers in public universities of Pakistan. Mediterranean Journal of Social Sciences, 2(4), 97-97.

Bandy, J. (2016). What is service learning or community engagement. Center for Teaching, Vanderbilt University. https://cft. vanderbilt. edu/guides-subpages/teaching-through-community-engagement. 
Brookfield, S. (1984). Self-directed adult learning: A critical paradigm. Adult Education Quarterly, 35(2), 59-71.

Collins, N., Bekenova, K., \& Kagarmanova, A. (2018). EL-CSID Policy Brief 5: Health diplomacy of the European Union and its member states in Central Asia. Institute for European Studies Issue 2018/5.

Gall, M. D., Borg, W. R., \& Gall, J. P. (1996). Educational research: An introduction: Longman Publishing.

Ignoffo, R., Chan, L., Knapp, K., Chan, E., Ip, E., Bandy, J., . . . Galanto, J. S. (2017). Efficient and effective precepting of pharmacy students in acute and ambulatory care rotations: A Delphi expert panel study. American Journal of HealthSystem Pharmacy, 74(19), 1570-1578.

Kazmi, S. W., \& Quran, H. (2005). Role of education in globalization: A case for Pakistan. SAARC journal of human resource development, 1(1), 90-107.

Khalid, S. M., \& Khan, M. F. (2006). Pakistan: The state of education. The Muslim World, 96(2), 305-322.

Khan, A., Khan, S., Zia-Ul-Islam, S., \& Khan, M. (2017). Communication Skills of a Teacher and Its Role in the Development of the Students' Academic Success. Journal of Education and Practice, 8(1), 18-21.

Mehboob, F., \& Othman, N. (2020). Examining the Links Leading to Behavioral Support for Change: An Expectancy Theory Perspective. International Journal of Social Sciences and Economic Review, 1-08.

Nugmanova, M., Mikkola, H., Rozanov, A., \& Komleva, V. (2020). Education, Human Rights and Peace in Sustainable Development: BoD-Books on Demand.

Robinson, C., Phillips, L., \& Quennerstedt, A. (2020). Human rights education: developing a theoretical understanding of teachers' responsibilities. Educational Review, 72(2), 220-241.

Saeed, M. (2007). Education System of Pakistan and the UK: Comparisons in Context to Inter-provincial and Inter-countries Reflections. Bulletin of Education \& Research, 29(2), 43-57.

Tawil, S., \& Locatelli, R. (2015). Rethinking Education: Towards a Global Comon Good: Paris: Unesco. 